\title{
Rapidly declining skeletal muscle mass predicts poor prognosis of hepatocellular carcinoma treated with transcatheter intra- arterial therapies
}

Takamasa Kobayashi, Hirokazu Kawai,, Oki Nakano, Satoshi Abe, Hiroteru Kamimura, Akira Sakamaki, Kenya Kamimura, Atsunori Tsuchiya, Masaaki Takamura, Satoshi Yamagiwa and Shuji Terai

\begin{abstract}
Background: The impact of sarcopenia on the prognosis of patients with hepatocellular carcinoma (HCC) who receive transcatheter intra-arterial therapies, including transcatheter arterial chemoembolization and transcatheter arterial infusion chemotherapy, remains unclear. We investigated the prognostic value of skeletal muscle loss (SML) stratified by cutoffs for sarcopenia and rate of change in skeletal muscle mass over 6 months.

Methods: We retrospectively evaluated 102 patients with HCC treated with transcatheter intra-arterial therapies between 2005 and 2015. Computed tomography images of the third lumbar vertebra (L3) were analyzed to obtain the skeletal muscle area normalized for the height squared, defined as the skeletal muscle index at L3 (L3 SMI), before and 6 months after treatment. Low or high SMI was defined using cutoff values of $42 \mathrm{~cm}^{2} / \mathrm{m}^{2}$ in men and $38 \mathrm{~cm}^{2} / \mathrm{m}^{2}$ in women. The rate of change in skeletal muscle mass ( $\Delta \mathrm{L} 3 \mathrm{SMI}$ ) over 6 months was calculated. Overall survival (OS) was compared in groups classified by baseline L3 SMI and $\Delta$ L3 SMl; prognostic significance was assessed with univariate and multivariate analyses, using Cox proportional hazards models.

Results: OS did not differ significantly between groups with low $(n=31)$ and high $(n=71)$ SMl at baseline $(P=0.172)$, but OS was significantly poorer in patients with SML $(n=41)$, defined as $\Delta \mathrm{L} 3 \mathrm{SMl}<-4.6 \%$ over 6 months than in those without SML ( $n=61, P=0.018$ ). On multivariate analysis, SML (hazard ratio [HR], 1.675; 95\% confidence interval [CI], $1.031-2.721 ; P=0.037)$, serum alpha-fetoprotein $\geq 20 \mathrm{ng} / \mathrm{mL}(H R, 2.550 ; 95 \% \mathrm{Cl}, 1.440-4.515 ; P=0.001)$, and maximum tumor diameter $\geq 30 \mathrm{~mm}(\mathrm{HR}, 1.925 ; 95 \% \mathrm{Cl}, 1.166-3.179 ; P=0.010)$ were independent predictors of poor OS. Baseline L3 SMI was not significantly associated with OS (HR, 1.405; 95\% Cl, 0.861-2.293; $P=0.174)$.

Conclusions: $\Delta \mathrm{L} 3 \mathrm{SMI}$ was an independent prognostic factor in patients with HCC treated with transcatheter intraarterial therapies. Further study is required to reveal whether prevention of skeletal muscle depletion might be a new therapeutic strategy to contribute to improved clinical outcomes in patients with HCC.
\end{abstract}

Keywords: Skeletal muscle loss, Sarcopenia, Hepatocellular carcinoma, Transcatheter arterial chemoembolization, Transcatheter arterial infusion chemotherapy, Prognosis

\footnotetext{
* Correspondence: kawaih@med.niigata-u.ac.jp

Division of Gastroenterology and Hepatology, Niigata University Graduate

School of Medical and Dental Sciences, 1-757 Asahimachi-dori Chuo-ku,

Niigata 951-8510, Japan
}

(c) The Author(s). 2018 Open Access This article is distributed under the terms of the Creative Commons Attribution 4.0 International License (http://creativecommons.org/licenses/by/4.0/), which permits unrestricted use, distribution, and reproduction in any medium, provided you give appropriate credit to the original author(s) and the source, provide a link to the Creative Commons license, and indicate if changes were made. The Creative Commons Public Domain Dedication waiver (http://creativecommons.org/publicdomain/zero/1.0/) applies to the data made available in this article, unless otherwise stated. 


\section{Background}

Hepatocellular carcinoma (HCC) is one of the most common malignancies worldwide and a major cause of cancer mortality [1]. Recent advances in therapeutic modalities, including hepatic resection, percutaneous ethanol injection, radiofrequency ablation (RFA), and transplantation, have substantially improved the prognosis of patients with HCC [2-6]. Many patients with advanced HCC or severely impaired liver function, however, are beyond the indications for these radical treatments. Transcatheter intra-arterial therapies, including transcatheter arterial chemoembolization (TACE) and transcatheter arterial infusion chemotherapy (TAI), are widely used in advanced HCC. Although these treatments are not curative and yield a lower cumulative survival rate than surgical resection and local ablation therapies [7], the prognosis of patients receiving these interventions fluctuates according to various factors, such as hepatic functional reserve; tumor number, diameter, and distribution in the liver; and treatment efficacy [8-11].

Sarcopenia is a geriatric syndrome characterized by progressive and generalized loss of skeletal muscle mass and strength. The etiology of sarcopenia is multifactorial, comprising primary causes associated with age and secondary causes related to reduced physical activity, diseases, and nutritional disorders [12, 13]. Several recent studies have reported close associations between sarcopenia and poor clinical outcomes in patients with various types and stages of malignancies, including HCC $[14,15]$. Furthermore, loss of skeletal muscle mass has been associated with poorer overall survival (OS) and disease-free survival in patients with HCC treated with surgical resection or RFA [16-20]. However, the impact of sarcopenia on the prognosis of patients with HCC who receive transcatheter intra-arterial therapies has not yet been assessed.

We hypothesized that sarcopenia may affect the clinical outcomes of patients with HCC who experience gradual deterioration of hepatic function and nutritional status during repeated rounds of transcatheter intra-arterial therapy. Therefore, we retrospectively investigated the prognostic significance of loss of skeletal muscle mass in a group of these patients, stratified by cutoff values for sarcopenia [21]. We also evaluated the prognostic value of the rate of change in skeletal muscle mass over 6 months in this group.

\section{Methods}

\section{Patients}

In the present study, we retrospectively analyzed patients with HCC who underwent TACE and/or TAI as initial treatment at Niigata University Medical and Dental Hospital between January 2005 and December 2015. HCC was diagnosed principally based on its enhancement pattern on dynamic computed tomography (CT) or dynamic magnetic resonance imaging (MRI), exhibiting contrast enhancement in the arterial phase followed by rapid washout in the portal or equilibrium phase. Patients who had undergone a CT examination within 30 days prior to treatment and about 6 months (range, 90-270 days) after treatment were included in the study, while patients who received treatment either initially or additionally with curative methods, including surgical resection or RFA, were excluded.

This retrospective study was approved by the ethics committee of the Niigata University School of Medicine (approval number 2442) and was conducted in accordance with the 1975 Helsinki Declaration. Because of the anonymous nature of the data, the requirement for additional informed consent to participate in the study was waived.

\section{Treatment procedure}

TACE and/or TAI were performed according to the clinical practice guidelines for HCC of the Japan Society of Hepatology [22]. Briefly, TACE or TAI is recommended for patients with multiple tumors and Child-Pugh class A or B hepatic impairment severity. The TAI procedure consists of the injection of cisplatin (IA-call ${ }^{\oplus}$; Nippon Kayaku Co., Ltd., Tokyo, Japan), miriplatin (MIRIPLA ${ }^{\oplus}$ Dainippon Sumitomo Pharma Co., Ltd., Osaka, Japan), or an emulsion of epirubicin (Farmorubicin'; Pfizer Japan Inc., Tokyo, Japan) in lipiodol into hepatic arteries, including tumor-nourishing arteries. TACE includes subsequent embolization of the feeding arteries with gelatin sponge particles (Gelpart ${ }^{\circledR}$; Nihonkayaku, Tokyo, Japan) following the TAI procedure. TAI without embolization was implemented when multiple tumors were extensively distributed bilaterally in the lobes of the liver, the arterial anatomy precluded a super-selective injection, or there were significant arteriovenous fistulas or tumor thrombi in the main trunk of the portal vein.

\section{Skeletal muscle mass measurement}

Skeletal muscle areas were measured on axial sections at the level of the third lumbar vertebra (L3) of pre- and post-treatment CT images, using SliceOmatic software (version 5.0; TomoVision Inc., Montreal, Canada). The psoas, erector spinae, quadratus lumborum, transversus abdominis, external and internal oblique, and rectus abdominis muscles were delineated by density thresholds ranging from -29 to 150 Hounsfield units [23]. The muscle area $\left(\mathrm{cm}^{2}\right)$ at the L3 level was normalized by the square of height $\left(\mathrm{m}^{2}\right)$ to obtain the skeletal muscle index at L3 (L3 SMI, $\mathrm{cm}^{2} / \mathrm{m}^{2}$ ). Patients were classified into low or high SMI groups based on cutoff values of $42 \mathrm{~cm}^{2} / \mathrm{m}^{2}$ in men and $38 \mathrm{~cm}^{2} / \mathrm{m}^{2}$ in women, values 
recommended in the guidelines for sarcopenia in liver disease described by the Japan Society of Hepatology [21].

The rate of change in skeletal muscle mass over 6 months was calculated using the following formula: rate of change in skeletal muscle mass over 6 months $(\Delta \mathrm{L} 3 \mathrm{SMI}, \%)=(\mathrm{L} 3 \mathrm{SMI}$ on post-treatment $\mathrm{CT}-\mathrm{L} 3 \mathrm{SMI}$ on pre-treatment $\mathrm{CT}) /(\mathrm{L} 3 \mathrm{SMI}$ on pre-treatment CT)/ (days between pre- and post-treatment CT examinations) $\times 180 \times 100$. The cutoff value of $\Delta \mathrm{L} 3 \mathrm{SMI}$ was determined by optimal stratification of survival based on the most significant $P$ value in log-rank statistics $[24,25]$.

\section{Clinical data}

Retrospectively collected demographic and clinical data included age, sex, and body mass index (BMI); hepatitis $B$ virus (HBV) surface antigen; anti-hepatitis $C$ virus $(\mathrm{HCV})$ antibody; serum concentrations of alanine aminotransferase (ALT), total bilirubin, albumin, and alpha-fetoprotein (AFP); platelet count; Child-Pugh classification; TNM stage according to the Liver Cancer Study Group of Japan [26]; maximum tumor diameter; number of tumors; presence or absence of branched-chain amino acid (BCAA) supplementation; number of sessions of transcatheter intra-arterial therapy between the pre- and post-treatment CT examinations; transcatheter intra-arterial treatment modality; treatment response evaluated according to the Modified Response Evaluation Criteria in Solid Tumors (mRECIST) [27]; and cause of death.

\section{Statistical analysis}

Continuous variables expressed as median and range were compared using Mann-Whitney $U$ tests, and categorical variables expressed as number and percentage were compared using Fisher's exact tests or chi-squared tests. Survival days were counted from the date of pre-treatment CT. The Kaplan-Meier method was used to estimate survival rates, which were then compared using log-rank tests. The prognostic significance of covariates was assessed with univariate and multivariate analyses using a Cox proportional hazards model and expressed as hazard ratios (HRs) and 95\% confidence intervals (CIs). All variables significant in univariate analyses were entered into multivariate models. All statistical analyses were performed using IBM SPSS Version 21 Statistics software (IBM Corp., Armonk, NY, USA). All tests were two-sided, and $P$ values $<0.05$ were considered statistically significant.

\section{Results}

\section{Baseline demographic and clinical characteristics of patients}

Of the 621 consecutive patients admitted to our hospital for HCC treatment between January 2005 and December 2015, 102 were deemed eligible for participation in the current study; the baseline demographic and clinical characteristics of these patients are shown in Table 1. The median observation period was 733 days (range, 153-3278 days). The median age was 69 years (range,

Table 1 Baseline demographic and clinical characteristics

\begin{tabular}{|c|c|}
\hline Characteristics & Value \\
\hline Number of patients & 102 \\
\hline Observation period, days, median [range] & $733[153-3278]$ \\
\hline Age, years, median [range] & 69 [34-89] \\
\hline Sex (men), $n(\%)$ & $70(68.6)$ \\
\hline BMl in men, $\mathrm{kg} / \mathrm{m}^{2}$, median [range] & $23.5[16.2-33.8]$ \\
\hline BMl in women, $\mathrm{kg} / \mathrm{m}^{2}$, median [range] & $23.0[16.0-37.5]$ \\
\hline $\begin{array}{l}\text { Baseline } \mathrm{L} 3 \mathrm{SMI} \text { in men, } \mathrm{cm}^{2} / \mathrm{m}^{2} \text {, median } \\
\text { [range] }\end{array}$ & $47.1[31.5-64.4]$ \\
\hline $\begin{array}{l}\text { Baseline L3 SMI in women, } \mathrm{cm}^{2} / \mathrm{m}^{2} \text {, median } \\
\text { [range] }\end{array}$ & $36.5[25.6-55.6]$ \\
\hline \multicolumn{2}{|l|}{ Etiology, $n(\%)$} \\
\hline HBV & $11(10.8)$ \\
\hline $\mathrm{HCV}$ & $50(49.0)$ \\
\hline NBNC & $41(40.2)$ \\
\hline Alcohol & $26(25.5)$ \\
\hline $\mathrm{NASH}$ & $7(6.9)$ \\
\hline PBC & $2(2.0)$ \\
\hline Cryptogenic & $6(5.9)$ \\
\hline ALT, U/L, median [range] & 37 [9-243] \\
\hline Total bilirubin, mg/dL, median [range] & $1.0[0.4-3.5]$ \\
\hline Albumin, g/dL, median [range] & $3.7[2.0-4.9]$ \\
\hline Platelet count, $\times 10^{4} / \mu \mathrm{L}$, median [range] & $12.1[2.2-80.9]$ \\
\hline Child-Pugh classification (A/B/C), n (\%) & $68(66.7) / 34(33.3) / 0(0)$ \\
\hline AFP, ng/mL, median [range] & $21.8[1.0-633,900]$ \\
\hline TNM stage (I/II/III/IV), n (\%) & $\begin{array}{l}11(10.8) / 22(21.6) / \\
46(45.1) / 23(22.5)\end{array}$ \\
\hline Maximum tumor diameter, mm, median [range] & $32[9-198]$ \\
\hline Number of tumors (solitary/multiple), $n$ (\%) & 29(28.4)/73(71.6) \\
\hline $\begin{array}{l}\text { Treatment sessions between } \mathrm{CT} \text { exams, } \\
\text { sessions, median [range] }\end{array}$ & $1(1-6)$ \\
\hline Treatment modality (TACE/TAI/TACE+TAI), $n(\%)$ & $\begin{array}{l}18(17.6) / 25(24.5) / \\
59(57.8)\end{array}$ \\
\hline mRECIST assessment (CR/PR/SD/PD), n (\%) & $\begin{array}{l}18(17.6) / 26(25.5) / \\
9(8.8) / 49(48.0)\end{array}$ \\
\hline $\begin{array}{l}\text { BCAA supplementation (presence/absence), } n \\
(\%)\end{array}$ & $72(70.6) / 30(29.4)$ \\
\hline $\begin{array}{l}\text { Cause of death (liver-related/infection/Gl } \\
\text { bleeding/others/unknown), } n\end{array}$ & $57 / 7 / 2 / 4 / 2$ \\
\hline
\end{tabular}

$B M I$ body mass index, $L 3 S M I$ skeletal muscle index at third lumber vertebral level, $H B V$ hepatitis $B$ virus, $H C V$ hepatitis $C$ virus, NBNC non-B non- $C, N A S H$ non-alcoholic steatohepatitis, $P B C$ primary biliary cholangitis, $A L T$ alanine aminotransferase, AFP alpha-fetoprotein, TACE transcatheter arterial chemoembolization, TAI transcatheter arterial infusion chemotherapy, mRECIST Modified Response Evaluation Criteria in Solid Tumors, $C R$ complete response, $P R$ partial response, $S D$ stable disease, $P D$ progressive disease, $B C A A$ branchedchain amino acid, $G$ gastrointestinal 
34-89 years), and 70 patients $(68.6 \%)$ were men. The median L3 SMI on pre-treatment CT in men and women was $47.1 \mathrm{~cm}^{2} / \mathrm{m}^{2}$ (range, $31.5-64.4 \mathrm{~cm}^{2} / \mathrm{m}^{2}$ ) and $36.5 \mathrm{~cm}^{2} / \mathrm{m}^{2}$ (range, $25.6-55.6 \mathrm{~cm}^{2} / \mathrm{m}^{2}$ ), respectively. Fifty-nine patients $(57.8 \%)$ received a combination of TACE and TAI. A total of 167 treatment sessions were administered; among these, adverse events occurred in nine sessions, including prolonged fever in six sessions and liver function impairment in three sessions. No treatment-related deaths occurred. Seventy-two patients (70.6\%) died during the study period, with liver-related death (57 patients, 79.2\%) the leading cause of mortality.

\section{Association between baseline L3 SMI and survival}

Thirty-one patients (30.4\%; 14 men and 17 women) were classified into the low SMI group at baseline, whereas 71 patients (69.6\%; 56 men and 15 women) were classified into the high SMI group (Table 2). Patient age $(P=$ $0.001)$ and the proportion of women $(P=0.001)$ were significantly higher in the low SMI group than in the high SMI group. BMI was significantly higher in both men $(P<0.001)$ and women $(P=0.009)$ with high SMI than in those with low SMI. The most prevalent etiology of HCC was HCV infection in the low SMI group, and non- $B$ non- $C$ hepatitis in the high SMI group $(P=$ 0.003). There were no significant differences in Child-Pugh classification, TNM stage, or BCAA supplementation between the low and high SMI groups.

The OS rate tended to be higher in the high SMI group than in the low SMI group $(P=0.172)$, as shown in Fig. 1. Univariate analysis using a Cox proportional hazards model revealed no significant association between baseline L3 SMI and OS rate (HR, 1.405; 95\% CI, $0.861-2.293 ; P=0.174)$.

\section{Association between rate of change in skeletal muscle mass and survival}

The cutoff value for $\Delta \mathrm{L} 3 \mathrm{SMI}$ was determined to be $4.6 \%$ over 6 months, according to the optimization method for classification [24, 25]. A sharp decrease in skeletal muscle mass less than the cutoff value was defined as skeletal muscle loss (SML); other decreases were defined as non-skeletal muscle loss (non-SML). Of the 102 study patients, 41 (40.2\%; 30 men and 11 women) were classified into the SML group, and 61 (59.8\%; 40 men and 21 women) were classified into the non-SML group (Table 3). Comparison of the demographic and clinical characteristics of patients in the SML and non-SML groups revealed that the observation period was significantly shorter and the serum albumin level significantly lower in the SML group than in the non-SML group. The SML group was also characterized by features of more advanced tumor progression, such as higher serum AFP level and larger tumor size.
Univariate and multivariate analyses based on a Cox proportional hazards model were performed to identify independent predictors of survival (Table 4). Univariate analysis showed that SML; serum level of total bilirubin $\geq 1.5 \mathrm{mg} / \mathrm{dL}$, albumin $<3.5 \mathrm{~g} / \mathrm{dL}$, and AFP $\geq 20 \mathrm{ng} / \mathrm{mL}$; maximum tumor diameter $\geq 30 \mathrm{~mm}$; and progressive disease in response to treatment were significantly associated with poor OS. Multivariate analysis revealed that SML (HR, 1.675; 95\% CI, 1.031-2.721; $P=0.037$ ), serum AFP $\geq 20 \mathrm{ng} / \mathrm{mL} \quad(\mathrm{HR}, 2.550 ; 95 \%$ CI, $1.440-4.515 ; P=$ 0.001 ), and maximum tumor diameter $\geq 30 \mathrm{~mm}$ (HR, 1.925; 95\% CI, 1.166-3.179; $P=0.010$ ) were independently predictive of poor OS (Fig. 2).

\section{Discussion}

This retrospective study evaluated whether baseline skeletal muscle mass and its rate of change over 6 months were prognostic factors for OS in patients with $\mathrm{HCC}$ treated with transcatheter intra-arterial therapies. To our knowledge, this study is the first to show that the rate of change in skeletal muscle mass over 6 months was an independent indicator of clinical outcomes in these patients.

Prognostic factors that have been previously identified in patients with HCC treated with TACE or TAI include hepatic functional reserve; tumor-specific factors, such as number, diameter, vascular invasion, and distribution in the liver; and serum AFP concentrations [8-11]. The present study additionally revealed that the 6 -month rate of change in skeletal muscle mass was predictive of survival in these patients. In previous studies, an association between change in skeletal muscle mass during chemotherapy and prognosis has been demonstrated in patients with various malignancies other than HCC [2832]; these findings indicate that the same association may be applied to predict outcomes in patients with HCC undergoing chemotherapeutic treatment. Because CT examinations are usually repeated at intervals shorter than 6 months as part of the clinical workup for patients with $\mathrm{HCC}$, it is quite feasible to practically apply our method of quantification of skeletal muscle mass.

Skeletal muscle mass has been reported to decline by approximately $1.4 \%$ per year owing to physiological aging [33]. In patients with cirrhosis, skeletal muscle is lost more rapidly, declining by about $2.2 \%$ per year [34]. The present study found that patients with HCC treated with transcatheter intra-arterial therapies showed drastic decreases in skeletal muscle mass, with a median rate of $-3.5 \%$ over 6 months. Furthermore, SML $<-4.6 \%$ over 6 months was significantly associated with poorer OS. These findings suggest that a rapid loss of skeletal muscle mass induced by deterioration of hepatic function is associated with poor clinical outcomes in patients with chronic liver disease. 
Table 2 Comparison of demographic and clinical characteristics between low and high skeletal muscle index groups

\begin{tabular}{|c|c|c|c|}
\hline Variables & Low SMI (No. = 31) & High SMI (No. =71) & $P$ value \\
\hline Observation period, days, median [range] & $740[161-3278]$ & 706 [153-2902] & 0.708 \\
\hline Age, years, median [range] & 74 [53-89] & $66[34-86]$ & 0.001 \\
\hline Sex (men/women), $n$ & $14 / 17$ & $56 / 15$ & 0.001 \\
\hline BMI in men, $\mathrm{kg} / \mathrm{m}^{2}$, median [range] & $21.0[16.2-25.8]$ & $24.4[19.7-33.8]$ & $<0.001$ \\
\hline BMl in women, $\mathrm{kg} / \mathrm{m}^{2}$, median [range] & $22.0[16.0-37.5]$ & $23.9[20.7-34.7]$ & 0.009 \\
\hline Baseline L3 SMI in men, $\mathrm{cm}^{2} / \mathrm{m}^{2}$, median [range] & $36.8[31.5-40.7]$ & $48.2[42.2-64.4]$ & $<0.001$ \\
\hline Baseline L3 SMI in women, $\mathrm{cm}^{2} / \mathrm{m}^{2}$, median [range] & $34.4[25.6-36.5]$ & $41.7[38.1-55.6]$ & $<0.001$ \\
\hline Etiology (HBV/HCV/NBNC), $n$ & $1 / 23 / 7$ & $10 / 27 / 34$ & 0.003 \\
\hline ALT, U/L, median [range] & 38 [13-123] & 37 [9-243] & 0.945 \\
\hline Total bilirubin, mg/dL, median [range] & $0.8[0.5-2.7]$ & $1.0[0.4-3.5]$ & 0.107 \\
\hline Albumin, g/dL, median [range] & $3.6[2.1-4.7]$ & $3.7[2.0-4.9]$ & 0.249 \\
\hline Platelet count, $\times 10^{4} / \mathrm{\mu L}$, median [range] & $11.6[3.2-61.5]$ & $12.1[2.2-80.9]$ & 0.636 \\
\hline Child-Pugh classification (A/B), $n$ & $20 / 11$ & $48 / 23$ & 0.821 \\
\hline AFP, ng/mL, median [range] & $19.5[2.1-633,900]$ & $24.7[1.0-285,973]$ & 0.881 \\
\hline TNM stage $(I+\|/ I\|+I V), n$ & $9 / 22$ & $24 / 47$ & 0.818 \\
\hline Maximum tumor diameter, mm, median [range] & $26[13-150]$ & 36 [9-198] & 0.662 \\
\hline Number of tumors (solitary/multiple), $n$ & $9 / 22$ & $20 / 51$ & 1.000 \\
\hline Treatment sessions between $C T$ exams ( $1 / \geq 2$, sessions), $n$ & $17 / 14$ & $42 / 29$ & 0.828 \\
\hline mRECIST assessment (non-PD/PD), $n$ & $16 / 15$ & $37 / 34$ & 1.000 \\
\hline BCAA supplementation (presence/absence), $n$ & $22 / 9$ & $50 / 21$ & 1.000 \\
\hline
\end{tabular}

$B M I$ body mass index, $L 3 S M I$ skeletal muscle index at third lumber vertebral level, $H B V$ hepatitis $B$ virus, $H C V$ hepatitis $C$ virus, NBNC non-B non-C, $A L T$ alanine aminotransferase, AFP alpha-fetoprotein, $C T$ computed tomography, mRECIST Modified Response Evaluation Criteria in Solid Tumors, PD progressive disease, BCAA branched-chain amino acid

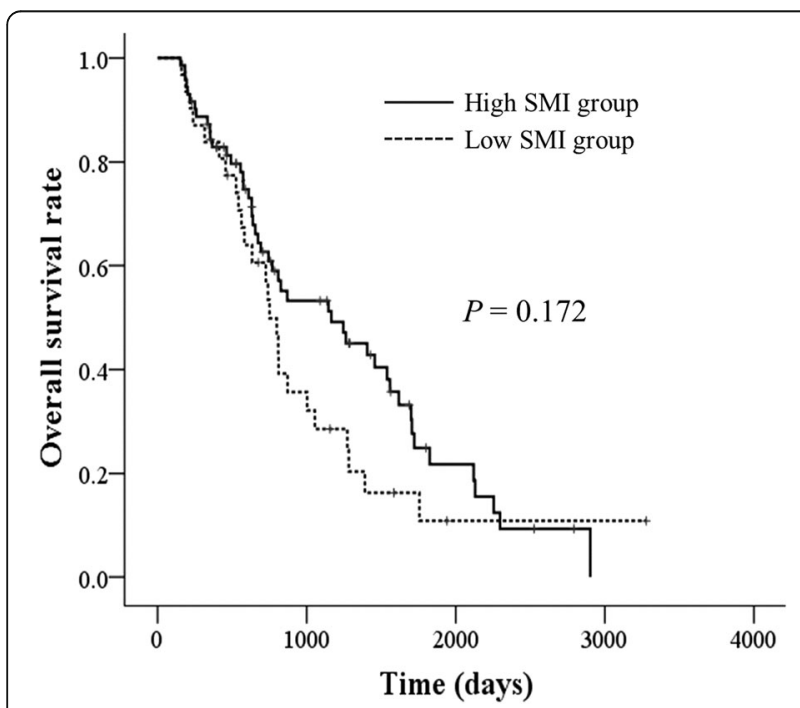

Fig. 1 Overall survival rates in groups of patients with low and high skeletal muscle index (SMI) at the level of the third lumbar vertebra, as determined by cutoff values of $42 \mathrm{~cm}^{2} / \mathrm{m}^{2}$ for men and $38 \mathrm{~cm}^{2}$ / $\mathrm{m}^{2}$ for women $(P=0.172)$. Survival rates were estimated with the Kaplan-Meier method and compared using log-rank tests
In the current study, skeletal muscle mass at baseline was not predictive of clinical outcomes, in contrast to the findings of previous studies in which patients with HCC were treated with modalities other than transcatheter intra-arterial therapies [14-20]. This discrepancy may be the result of differences in hepatic functional reserve or tumor progression among the enrolled patients. Guidelines for the treatment of $\mathrm{HCC}$ recommend radical therapies in patients with preserved liver function and limited tumor progression [22], who often have good nutritional status and preserved skeletal muscle mass. In contrast, most patients who undergo transcatheter intra-arterial therapies have more severely impaired liver function, or tumors in more advanced stages. These adverse conditions may have a considerable impact on outcomes, irrespective of skeletal muscle mass at baseline.

Although we did not assess the mechanisms responsible for the rapid loss of skeletal muscle in the patients with $\mathrm{HCC}$ in the present study, the phenomenon may be associated with protein-energy malnutrition (PEM). PEM is frequently observed in patients with liver disease, and facilitates catabolism and loss of skeletal muscle mass [35-37]. In addition, patients with impaired liver function are often deficient in vitamin D or carnitine, which might cause skeletal muscle atrophy [38, 39]. 
Table 3 Comparison of demographic and clinical characteristics between skeletal muscle loss and non-skeletal muscle loss groups

\begin{tabular}{|c|c|c|c|}
\hline Variables & SML $($ No. $=41)$ & Non-SML (No. $=61)$ & $P$ value \\
\hline Observation period, days, median [range] & $632[153-2902]$ & 785 [184-3278] & 0.021 \\
\hline Age, years, median [range] & 67 [38-89] & $72[34-88]$ & 0.231 \\
\hline Sex (men/women), $n$ & $30 / 11$ & $40 / 21$ & 0.515 \\
\hline BMI in men, $\mathrm{kg} / \mathrm{m}^{2}$, median [range] & $23.5[17.6-32.7]$ & $23.5[16.2-33.8]$ & 0.972 \\
\hline BMI in women, $\mathrm{kg} / \mathrm{m}^{2}$, median [range] & $22.8[16.0-34.7]$ & $23.2[17.1-37.5]$ & 0.858 \\
\hline$\Delta \mathrm{L} 3 \mathrm{SMI}$ in men, \%, median [range] & $-10.1[-34.2--4.7]$ & $-0.8[-4.3-14.2]$ & $<0.001$ \\
\hline$\Delta \mathrm{L} 3 \mathrm{SMl}$ in women, \%, median [range] & $-8.3[-25.2--5.3]$ & $1.4[-4.5-13.0]$ & $<0.001$ \\
\hline Etiology (HBV/HCV/NBNC), $n$ & $4 / 22 / 15$ & $7 / 28 / 26$ & 0.744 \\
\hline ALT, U/L, median [range] & $47(10-243)$ & $37(9-166)$ & 0.188 \\
\hline Total bilirubin, mg/dL, median [range] & $1.1[0.4-2.4]$ & $0.9[0.5-3.5]$ & 0.423 \\
\hline Albumin, g/dL, median [range] & $3.6[2.1-4.7]$ & $3.7[2.0-4.9]$ & 0.026 \\
\hline Platelet count, $\times 10^{4} / \mu \mathrm{L}$, median [range] & $11.9[3.4-80.9]$ & $12.1[2.2-27.1]$ & 0.453 \\
\hline Child-Pugh classification (A/B), $n$ & $27 / 14$ & $41 / 20$ & 1.000 \\
\hline AFP, ng/mL, median [range] & $54[2.0-633,900]$ & $14[1.0-40,769]$ & 0.009 \\
\hline TNM stage $(I+\|/\| I \|+\mid V), n$ & $12 / 29$ & $21 / 40$ & 0.668 \\
\hline Maximum tumor diameter, mm, median [range] & $50[10-198]$ & 28 [9-120] & 0.009 \\
\hline Number of tumors (solitary/multiple), $n$ & $12 / 29$ & $17 / 44$ & 1.000 \\
\hline Treatment sessions between $C T$ exams ( $1 / \geq 2$, sessions), $n$ & $24 / 17$ & $35 / 26$ & 1.000 \\
\hline mRECIST assessment (non-PD/PD), $n$ & $18 / 23$ & $35 / 26$ & 0.227 \\
\hline BCAA supplementation (presence/absence), $n$ & $30 / 11$ & $42 / 19$ & 0.665 \\
\hline
\end{tabular}

$S M L$ skeletal muscle loss, $B M I$ body mass index, $\triangle L 3 S M I$ rate of change of skeletal muscle mass over 6 months, $H B V$ hepatitis $B$ virus, $H C V$ hepatitis $C$ virus, NBNC non-B non-C, ALT alanine aminotransferase, AFP alpha-fetoprotein, CT computed tomography, mRECIST Modified Response Evaluation Criteria in Solid Tumors, $P D$ progressive disease, $B C A A$ branched-chain amino acid

Table 4 Univariate and multivariate analysis using Cox proportional hazards model for overall survival

\begin{tabular}{|c|c|c|c|c|}
\hline \multirow[t]{2}{*}{ Variables } & \multicolumn{2}{|l|}{ Univariate analysis } & \multicolumn{2}{|l|}{ Multivariate analysis } \\
\hline & $\mathrm{HR}(95 \% \mathrm{Cl})$ & $P$ value & $\mathrm{HR}(95 \% \mathrm{Cl})$ & $P$ value \\
\hline Age, years, $\geq 70$ vs. $<70$ & $0.857(0.539-1.362)$ & 0.513 & & \\
\hline Sex, men vs. women & $1.354(0.814-2.255)$ & 0.243 & & \\
\hline $\mathrm{BMl}, \mathrm{kg} / \mathrm{m}^{2}, \geq 25.0$ vs. $<25.0$ & $0.731(0.444-1.204)$ & 0.218 & & \\
\hline Baseline L3 SMI, low SMI vs. high SMI & $1.405(0.861-2.293)$ & 0.174 & & \\
\hline$\Delta \mathrm{L} 3 \mathrm{SMI}, \mathrm{SML}$ vs. non-SML & $1.750(1.093-2.800)$ & 0.020 & $1.675(1.031-2.721)$ & 0.037 \\
\hline ALT, U/L, $\geq 30$ vs. $<30$ & $1.046(0.650-1.682)$ & 0.854 & & \\
\hline Total bilirubin, mg/dL, $\geq 1.5$ vs. $<1.5$ & $1.690(1.002-2.851)$ & 0.049 & $1.747(0.897-3.403)$ & 0.101 \\
\hline Albumin, $\mathrm{g} / \mathrm{dL}, \geq 3.5$ vs. $<3.5$ & $0.595(0.361-0.982)$ & 0.042 & $0.697(0.386-1.259)$ & 0.231 \\
\hline Platelet count, $\times 10^{4} / \mu \mathrm{L}, \geq 10.0$ vs. $<10.0$ & $0.971(0.607-1.552)$ & 0.902 & & \\
\hline Child-Pugh classification, A vs. B & $0.638(0.395-1.030)$ & 0.066 & & \\
\hline AFP, ng/mL, $\geq 20$ vs. $<20$ & $2.618(1.615-4.241)$ & $<0.001$ & $2.550(1.440-4.515)$ & 0.001 \\
\hline TNM stage, I + II vs. III + IV & $0.785(0.474-1.300)$ & 0.347 & & \\
\hline Maximum tumor diameter, mm, $\geq 30$ vs. $<30$ & $1.936(1.195-3.135)$ & 0.007 & $1.925(1.166-3.179)$ & 0.010 \\
\hline Number of tumors, solitary vs. multiple & $0.961(0.572-1.614)$ & 0.880 & & \\
\hline Treatment sessions between $C T$ exams, sessions, 1 vs. $\geq 2$ & $0.696(0.433-1.119)$ & 0.135 & & \\
\hline mRECIST assessment, non-PD vs. PD & $0.444(0.277-0.712)$ & 0.001 & $0.653(0.392-1.088)$ & 0.102 \\
\hline BCAA supplementation, presence vs. absence & $1.614(0.898-2.900)$ & 0.110 & & \\
\hline
\end{tabular}

$H R$ hazard ratio, $C I$ confidence interval, $S M L$ skeletal muscle loss, $B M I$ body mass index, $L 3$ SMI skeletal muscle index at third lumber vertebral level, $\triangle L 3$ SMI rate of change of skeletal muscle mass over 6 months, SML skeletal muscle loss, ALT alanine aminotransferase, AFP alpha-fetoprotein, CT computed tomography, mRECIST Modified Response Evaluation Criteria in Solid Tumors, $P D$ progressive disease, BCAA branched-chain amino acid 
$\mathbf{a}$

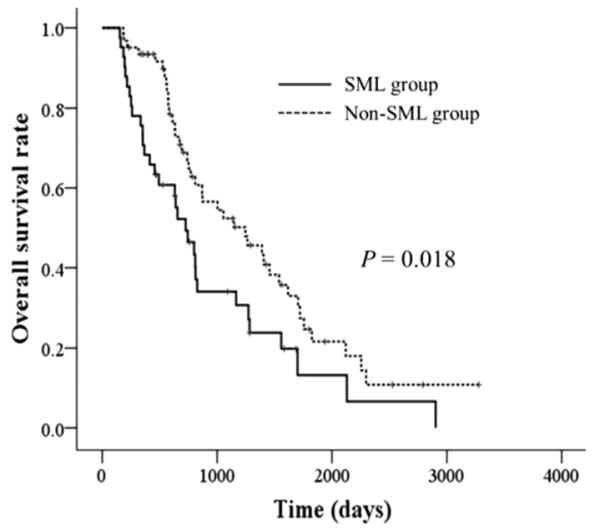

c

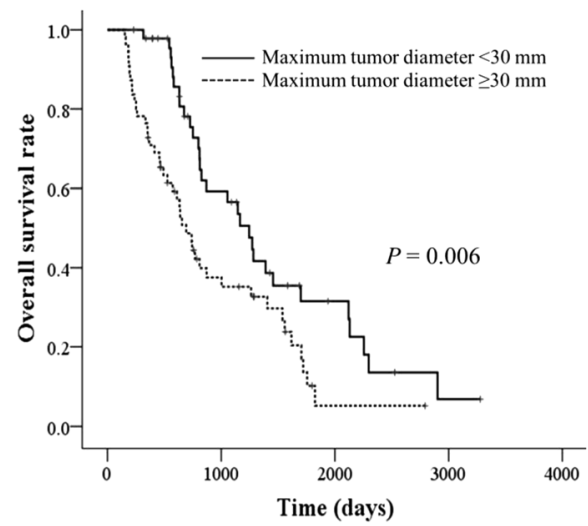

$\mathbf{b}$

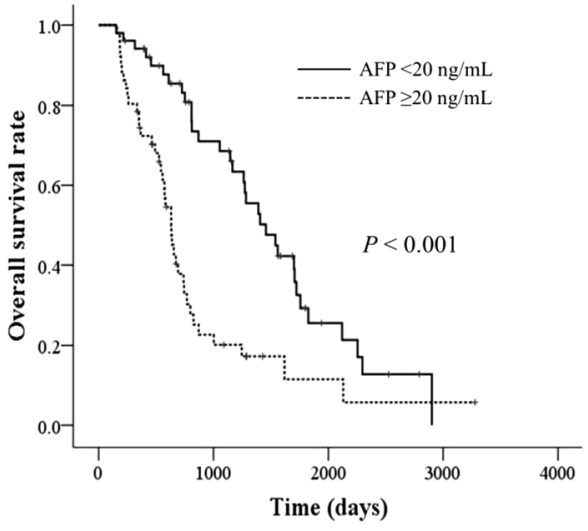

Fig. 2 Overall survival rates in patients (a) with skeletal muscle loss (SML) or non-SML $(P=0.018)$, (b) with alpha-fetoprotein (AFP) $<20$ ng/mL or $\geq 20 \mathrm{ng} / \mathrm{mL}(P<0.001)$, and $(\mathbf{c})$ with maximum tumor diameter $<30 \mathrm{~mm}$ or $\geq 30 \mathrm{~mm}(P=0.006)$. Survival rates were estimated with the Kaplan-Meier method and compared using log-rank tests

Most of the patients in our study had severely deteriorated liver function and $\mathrm{HCC}$ in advanced stages; these detrimental conditions may have led to rapid depletion of skeletal muscle.

Although prevention of SML has not been shown to improve the prognosis of patients with $\mathrm{HCC}$, dietary supplementation with BCAAs in patients with cirrhosis or HCC was found to preserve liver function and increase muscle protein synthesis by activating the mammalian target of rapamycin signaling [40, 41]. Vitamin D supplementation may also inhibit tumor progression [42-44] and increase muscle mass and strength [45-47]. Furthermore, supplementation with L-carnitine may prevent skeletal muscle atrophy by activating the insulin-like growth factor-1/AKT/p70S6 kinase pathway [48]. Physical exercise also has beneficial effects on muscles through attenuation of signaling pathways associated with skeletal muscle proteolysis in cachectic conditions and promotion of protein synthesis via anti-inflammatory and anti-oxidative effects [49, 50]. However, a recent study showed that exercise alone could not prevent a reduction in skeletal muscle mass, but that BCAA supplementation minimized skeletal muscle depletion in patients with HCC [51]. It will be necessary to investigate whether the conservation of skeletal muscle with a combination of nutritional support and exercise could improve the prognosis of patients with HCC, with the goal of developing a systematic strategy for the preservation of skeletal muscle in these patients.

The present study had several limitations. First, the study involved a relatively small number of patients who were treated at a single institution. Second, our study was retrospective in design, and we could not evaluate skeletal muscle strength and function. The assessment of not only skeletal muscle mass but also strength or function is needed to diagnose sarcopenia, according to guidelines [21]. Prospective studies assessing skeletal muscles comprehensively among larger numbers of patients with $\mathrm{HCC}$ are required to confirm our results.

\section{Conclusions}

In this study, we found that the rate of change in skeletal muscle mass over 6 months was an independent 
prognostic factor in patients with HCC treated with transcatheter intra-arterial therapies. In contrast, SML at baseline was not prognostic of clinical outcomes in these patients. Further study is required to reveal whether prevention of skeletal muscle depletion might contribute to improvement of clinical outcomes in patients with HCC, as a new therapeutic strategy.

\section{Abbreviations}

AFP: Alpha-fetoprotein; ALT: Alanine aminotransferase; BCAA: Branched-chain amino acid; BMl: Body mass index; Cl: Confidence interval; CT: Computed tomography; HBV: Hepatitis B virus; HCC: Hepatocellular carcinoma; HCV: Hepatitis C virus; HR: Hazard ratio; L3 SMI: Skeletal muscle index at the third lumbar vertebral level; mRECIST: Modified Response Evaluation Criteria in Solid Tumors; MRI: Magnetic resonance imaging; OS: Overall survival; PEM: Protein-energy malnutrition; RFA: Radiofrequency ablation; SML: Skeletal muscle loss; TACE: Transcatheter arterial chemoembolization;

TAl: Transcatheter arterial infusion chemotherapy

\section{Availability of data and materials}

The datasets used and/or analyzed in the current study are available from the corresponding author on reasonable request.

\section{Authors' contributions}

All authors contributed to the study design as well as collection and analysis of the data. TK, HK, and ON developed the study concept, performed statistical analysis, and drafted the manuscript. SA, HK, AS, KK, AT, MT, and SY were involved in data assembly and interpretation. ST supervised the study design and critically revised the manuscript. All authors approved the final version of the manuscript.

\section{Ethics approval and consent to participate}

This retrospective study was approved by the ethics committee of the Niigata University School of Medicine (approval number 2442) and was carried out in accordance with the 1975 Helsinki Declaration. Because of the anonymous nature of the data and the opt-out disclosed on our institution's homepage (http://www.med.niigata-u.ac.jp/contents/rinsyouken/naika03/ index.html), the requirement for additional informed consent to participate in this study was deemed unnecessary according to the Japanese national regulation "Ethical Guidelines for Medical and Health Research Involving Human Subjects" (https://www.mhlw.go.jp/file/06-Seisakujouhou-10600000Daijinkanboukouseikagakuka/0000080278.pdf).

\section{Consent for publication}

Not applicable.

\section{Competing interests}

The authors declare that they have no competing interests.

\section{Publisher's Note}

Springer Nature remains neutral with regard to jurisdictional claims in published maps and institutional affiliations.

Received: 18 December 2017 Accepted: 18 July 2018

Published online: 24 July 2018

\section{References}

1. Torre LA, Bray F, Siegel RL, Ferlay J, Lortet-Tieulent J, Jemal A. Global cancer statistics, 2012. CA Cancer J Clin. 2015:65:87-108.

2. Makuuchi M, Hasegawa $\mathrm{H}$, Yamazaki S. Ultrasonically guided subsegmentectomy. Surg Gynecol Obstet. 1985;161:346-50.

3. Ohtomo K, Furui S, Kokubo T, et al. Transcatheter arterial embolization (TAE) in treatment for hepatoma--analysis of three-year survivors. Radiat Med. 1985:3:176-80

4. Shiina S, Tagawa K, Niwa Y, et al. Percutaneous ethanol injection therapy for hepatocellular carcinoma: results in 146 patients. Am J Roentogenol. 1993; 160:1023-8.

5. Shiina S, Teratani T, Obi S, Hamamura K, Koike Y, Omata M. Nonsurgical treatment of hepatocellular carcinoma: from percutaneous ethanol injection therapy and percutaneous microwave coagulation therapy to radiofrequency ablation. Oncology. 2002;62:64-8.

6. Roayaie S, Frischer JS, Emre SH, et al. Long-term results with multimodal adjuvant therapy and liver transplantation for the treatment of hepatocellular carcinomas larger than 5 centimeters. Ann Surg. 2002;235:533-9.

7. Kudo M, Izumi N, Ichida T, et al. Report of the 19th follow-up survey of primary liver cancer in Japan. Hepatol Res. 2016;46:372-90.

8. Ogasawara S, Chiba T, Ooka Y, et al. A prognostic score for patients with intermediate-stage hepatocellular carcinoma treated with transarterial chemoembolization. PLoS One. 2015;10:e0125244.

9. Barman PM, Sharma P, Krishnamurthy V, et al. Predictors of mortality in patients with hepatocellular carcinoma undergoing transarterial chemoembolization. Dig Dis Sci. 2014;59:2821-5.

10. Hu HT, Kim JH, Lee LS, et al. Chemoembolization for hepatocellular carcinoma: multivariate analysis of predicting factors for tumor response and survival in a 362-patient cohort. J Vasc Interv Radiol. 2011;22:917-23.

11. Ikeda M, Maeda S, Ashihara H, Nagahama H, Tanaka M, Sasaki Y. Transcatheter arterial infusion chemotherapy with cisplatin-lipiodol suspension in patients with hepatocellular carcinoma. J Gastroenterol. 2010;45:60-7.

12. Cruz-Jentoft AJ, Baeyens JP, Bauer JM, et al. Sarcopenia: European consensus on definition and diagnosis: report of the European working group on sarcopenia in older people. Age Ageing. 2010;39:412-23.

13. Chen LK, Liu LK, Woo J, et al. Sarcopenia in Asia: consensus report of the Asian working Group for Sarcopenia. J Am Med Dir Assoc. 2014;15:95-101.

14. Iritani S, Imai K, Takai K, et al. Skeletal muscle depletion is an independent prognostic factor for hepatocellular carcinoma. J Gastroenterol. 2015;50:323-32.

15. Fujiwara N, Nakagawa H, Kudo Y, et al. Sarcopenia, intramuscular fat deposition, and visceral adiposity independently predict the outcomes of hepatocellular carcinoma. J Hepatol. 2015;63:131-40.

16. Higashi T, Hayashi H, Taki K, et al. Sarcopenia, but not visceral fat amount, is a risk factor of postoperative complications after major hepatectomy. Int 」 Clin Oncol. 2016;21:310-9.

17. Harimoto N, Yoshizumi T, Shimokawa M, et al. Sarcopenia is a poor prognostic factor following hepatic resection in patients 70 years of age and older with hepatocellular carcinoma. Hepatol Res. 2016:46:1247-55.

18. Kamachi S, Mizuta T, Otsuka T, et al. Sarcopenia is a risk factor for the recurrence of hepatocellular carcinoma after curative treatment. Hepatol Res. 2016;46:201-8.

19. Yabusaki N, Fujii T, Yamada S, et al. Adverse impact of low skeletal muscle index on the prognosis of hepatocellular carcinoma after hepatic resection. Int J Surg. 2016;30:136-42.

20. Harimoto N, Shirabe K, Yamashita Yl, et al. Sarcopenia as a predictor of prognosis in patients following hepatectomy for hepatocellular carcinoma. Br J Surg. 2013;100:1523-30.

21. Nishikawa H, Shiraki M, Hiramatsu A, Moriya K, Hino K, Nishiguchi S. Japan Society of Hepatology guidelines for sarcopenia in liver disease (1st edition): recommendation from the working group for creation of sarcopenia assessment criteria. Hepatol Res. 2016:46:951-63.

22. Kokudo N, Hasegawa K, Akahane M, et al. Evidence-based clinical practice guidelines for hepatocellular carcinoma: the Japan Society of Hepatology 2013 update (3rd JSH-HCC guidelines). Hepatol Res. 2015; https://doi.org/10.1111/hepr.12464

23. Mitsiopoulos N, Baumgartner RN, Heymsfield SB, Lyons W, Gallagher D, Ross R. Cadaver validation of skeletal muscle measurement by magnetic resonance imaging and computerized tomography. J Appl Physiol (1985). 1998:85:115-22.

24. Prado CM, Lieffers JR, McCargar $\amalg$, et al. Prevalence and clinical implications of sarcopenic obesity in patients with solid tumours of the respiratory and gastrointestinal tracts: a population-based study. Lancet Oncol. 2008;9:629-35.

25. van Vledder MG, Levolger S, Ayez N, Verhoef C, Tran TC, ljzermans JN. Body composition and outcome in patients undergoing resection of colorectal liver metastases. Br J Surg. 2012;99:550-7.

26. Liver Cancer Study Group of Japan. General Rules for the Clinical and Pathological Study of Primary Liver Cancer, 3rd English edition. Tokyo: Kanehara \& Co., Ltd.; 2010. p. 26-7.

27. Lencioni R, Llovet JM. Modified RECIST (mRECIST) assessment for hepatocellular carcinoma. Semin Liver Dis. 2010:30:52-60.

28. Stene GB, Helbostad JL, Amundsen T, et al. Changes in skeletal muscle mass during palliative chemotherapy in patients with advanced lung cancer. Acta Oncol. 2015;54:340-8. 
29. Miyamoto Y, Baba Y, Sakamoto Y, et al. Negative impact of skeletal muscle loss after systemic chemotherapy in patients with Unresectable colorectal Cancer. PLoS One. 2015;10:e0129742.

30. Choi Y, Oh DY, Kim TY, et al. Skeletal muscle depletion predicts the prognosis of patients with advanced pancreatic Cancer undergoing palliative chemotherapy, Independent of Body Mass Index. PLoS One. 2015;10:e0139749.

31. Blauwhoff-Buskermolen S, Versteeg KS, de van der Schueren MA, et al. Loss of muscle mass during chemotherapy is predictive for poor survival of patients with metastatic colorectal Cancer. J Clin Oncol. 2016;34:1339-44.

32. Rutten IJ, van Dijk DP, Kruitwagen RF, Beets-Tan RG, Olde Damink SW, van Gorp T. Loss of skeletal muscle during neoadjuvant chemotherapy is related to decreased survival in ovarian cancer patients. J Cachexia Sarcopenia Muscle. 2016;7:458-66.

33. Frontera WR, Hughes VA, Fielding RA, Fiatarone MA, Evans WJ, Roubenoff $R$. Aging of skeletal muscle: a 12-yr longitudinal study. J Appl Physiol (1985). 2000;88:1321-6.

34. Hanai T, Shiraki M, Ohnishi S, et al. Rapid skeletal muscle wasting predicts worse survival in patients with liver cirrhosis. Hepatol Res. 2016;46:743-51.

35. Nishikawa $\mathrm{H}$, Yoh $\mathrm{K}$, Enomoto $\mathrm{H}$, et al. Factors associated with proteinenergy malnutrition in chronic liver disease: analysis using indirect calorimetry. Medicine (Baltimore). 2016; https://doi.org/10.1097/MD. 0000000000002442.

36. Hanai T, Shiraki M, Nishimura K, et al. Sarcopenia impairs prognosis of patients with liver cirrhosis. Nutrition. 2015;31:193-9.

37. Moriwaki H, Miwa Y, Tajika M, Kato M, Fukushima H, Shiraki M. Branchedchain amino acids as a protein- and energy-source in liver cirrhosis. Biochem Biophys Res Commun. 2004:313:405-9.

38. Konstantakis C, Tselekouni P, Kalafateli M, Triantos C. Vitamin D deficiency in patients with liver cirrhosis. Ann Gastroenterol. 2016;29:297-306.

39. Flanagan JL, Simmons PA, Vehige J, Willcox MD, Garrett Q. Role of carnitine in disease. Nutr Metab (Lond). 2010; https://doi.org/10.1186/1743-7075-7-30.

40. Chen $L$, Chen $Y$, Wang $X$, et al. Efficacy and safety of oral branched-chain amino acid supplementation in patients undergoing interventions for hepatocellular carcinoma: a meta-analysis. Nutr J. 2015; https://doi.org/10. 1186/s12937-015-0056-6

41. Tsien C, Davuluri G, Singh D, et al. Metabolic and molecular responses to leucine-enriched branched chain amino acid supplementation in the skeletal muscle of alcoholic cirrhosis. Hepatology. 2015;61:2018-29.

42. Chiang KC, Yeh CN, Chen MF, Chen TC. Hepatocellular carcinoma and vitamin D: a review. J Gastroenterol Hepatol. 2011:26:1597-603.

43. Chiang $\mathrm{KC}$, Yen $\mathrm{CL}$, Yeh $\mathrm{CN}$, et al. Hepatocellular carcinoma cells express $25(\mathrm{OH}) \mathrm{D}-1 \mathrm{a}$-hydroxylase and are able to convert $25(\mathrm{OH}) \mathrm{D}$ to $1 \mathrm{a}, 25(\mathrm{OH})_{2} \mathrm{D}$, leading to the 25(OH)D-induced growth inhibition. J Steroid Biochem Mol Biol. 2015;154:47-52.

44. Huang J, Yang G, Huang Y, Kong W, Zhang S. 1,25(OH)2D3 inhibits the progression of hepatocellular carcinoma via downregulating HDAC2 and upregulating P21(WAFI/CIP1). Mol Med Rep. 2016;13:1373-80.

45. Girgis CM, Clifton-Bligh RJ, Hamrick MW, Holick MF, Gunton JE. The roles of vitamin D in skeletal muscle: form, function, and metabolism. Endocr Rev. 2013;34:33-83.

46. Cangussu LM, Nahas-Neto J, Orsatti CL, Bueloni-Dias FN, Nahas EA. Effect of vitamin D supplementation alone on muscle function in postmenopausal women: a randomized, double-blind, placebo-controlled clinical trial. Osteoporos Int. 2015;26:2413-21.

47. Bauer JM, Verlaan S, Bautmans I, et al. Effects of a vitamin D and leucineenriched whey protein nutritional supplement on measures of sarcopenia in older adults, the PROVIDE study: a randomized, double-blind, placebocontrolled trial. J Am Med Dir Assoc. 2015;16:740-7.

48. Montesano A, Senesi P, Luzi L, Benedini S, Terruzzi I. Potential therapeutic role of L-carnitine in skeletal muscle oxidative stress and atrophy conditions. Oxidative Med Cell Longev. 2015; https://doi.org/10.1155/2015/646171.

49. Gould DW, Lahart I, Carmichael AR, Koutedakis Y, Metsios GS. Cancer cachexia prevention via physical exercise: molecular mechanisms. J Cachexia Sarcopenia Muscle. 2013;4:111-24.

50. Bowen TS, Schuler G, Adams V. Skeletal muscle wasting in cachexia and sarcopenia: molecular pathophysiology and impact of exercise training. J Cachexia Sarcopenia Muscle. 2015;6:197-207.

51. Koya S, Kawaguchi T, Hashida R, et al. Effects of in-hospital exercise on liver function, physical ability, and muscle mass during treatment of hepatoma in patients with chronic liver disease. Hepatol Res. 2017; https://doi.org/10 1111/hepr.12718.

Ready to submit your research? Choose BMC and benefit from:

- fast, convenient online submission

- thorough peer review by experienced researchers in your field

- rapid publication on acceptance

- support for research data, including large and complex data types

- gold Open Access which fosters wider collaboration and increased citations

- maximum visibility for your research: over $100 \mathrm{M}$ website views per year

At $\mathrm{BMC}$, research is always in progress.

Learn more biomedcentral.com/submissions 